\title{
NICOLÁS MARÍA LÓPEZ CALERA, UNA SEMBLANZA INTELECTUAL *
}

\author{
Pedro Mercado Pacheco \\ Universidad de Granada
}

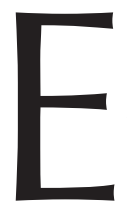

n primer lugar quisiera agradecer en nombre del Departamento de Filosofía del Derecho de la Universidad de Granada a la Sociedad Española de Filosofía Jurídica y Política y a la Comisión organizadora de estas jornadas la decisión de dedicar este acto a la memoria de los profesores N. M. ${ }^{a}$ LÓPEZ CAlera y G. PeCes-Barba que nos han dejado recientemente.

La razón de mi presencia en este acto es haber sido comisionado por mis compañeras y compañeros del Departamento para intervenir en este homenaje al profesor N. M. ${ }^{a}$ LÓPEZ CALERA. Y confieso que no ha sido fácil cumplir con el encargo. Por varias razones: por el propio carácter del acto, por el tipo de intervención que requiere y por la necesidad de condensar, dada la premura del tiempo del que dispongo, muchas cosas que uno no querría, ni podría dejar de decir.

Muchos de los presentes en estas jornadas han conocido y compartido con el profesor LÓPEZ CALERA otras jornadas y otros momentos. Puede que mis palabras no les aporten nada. Incluso algunos podrían hacer de él una semblanza mucho más fidedigna. Por ello, quisiera dirigir estas palabras especialmente a aquellos jóvenes o no tan jóvenes que no lo conocieron personalmente.

Quizás de él sólo sepan que fue un filósofo del derecho que ganó la cátedra muy joven, con tan solo 27 años, en una oposición en Madrid en 1966 en la que, según cuentan, destacó de forma muy brillante y que, tras un pequeño paréntesis de un año en la Universidad de Oviedo, volvió a Granada y dirigió el Departamento de Filosofía del Derecho de aquella Universidad durante más de cuarenta años.

Si tiene valor hoy hacer referencia a su trayectoria como filósofo del derecho es porque ella es fiel reflejo de la propia historia de nuestra disciplina durante los últimos cincuenta años.

Su formación inicial la realizó, según sus propias palabras, en una filosofía neoescolástica y en un contexto académico, el de los años sesenta, «cerrado y encerrado». Llegó a la Filosofía del Derecho de la mano del profesor A. DE Asís, del que siempre agradeció su apoyo personal y del que siempre le oí hablar de forma amable y con un profundo respeto y cariño. Él fue quien le propuso una tesis doctoral sobre J. CosTA, obligándole a estudiar el krausismo y la Institución Libre de enseñanza.

* Texto de la intervención realizada en el homenaje al profesor N. LÓPEZ CALERA en las XXIV Jornadas de la Sociedad Española de Filosofía Jurídica y Política, Santander, 15 de marzo de 2013. 
Tenía una opinión muy crítica de la filosofía del derecho de aquellos tiempos: «El neotomismo imperante era realmente pobre e ignorante de sus fuentes, además de reaccionario y fascista» y, sin duda, lo que más le repugnaba era «la manipulación de aquella doctrina cristiana para los peores y más malvados fines». Poco a poco fue apartándose de aquella filosofía del derecho que, perversa e hipócritamente, quería servir a los valores más excelentes del cristianismo. Como él mismo reconocía «fue un cambio muy duro, sobre todo por la catarsis interior e intelectual que tuve que efectuar y que conllevó desprecios y amenazas de todo tipo, desde personas muy queridas por mí hasta los Guerrilleros de Cristo Rey».

Un cambio fundamental que le llevó no sólo a una evolución de su pensamiento hacia otros temas y autores, sino, sobre todo, a una defensa comprometida de la democracia y de las libertades.

La ruptura con esa tradición tuvo quizá su momento de mayor expresión en la valiente actitud que mantuvo N. M. ${ }^{a}$ LÓPEZ CALERA en el tribunal que juzgaba las oposiciones a cátedra de 1973, cuando con el apoyo de los profesores DELGADO PINTO y GonZÁlez VicÉn, deciden votar por los profesores E. DíAz y J. J. Gil CREMAdES en detrimento de los candidatos oficialistas, y con el consiguiente escándalo de la academia.

Ese cambio y esa evolución se hicieron también patentes de forma paulatina en los temas y en los contenidos de los Anales de la Cátedra Francisco Suárez, la revista que dirigió durante más de cuarenta años y que supo con mucho esfuerzo mantener viva como referente en la filosofía jurídica y política.

En ese tiempo de mudanzas y de cambios, sus estancias en Alemania le sirvieron no sólo para profundizar en el estudio del krausismo, sino también y sobre todo en el idealismo alemán de KANT y HEGEL. Dos autores centrales en la obra de N. M. ${ }^{a}$ LÓPEZ CALERA. Y de paso le sirvieron para ponerse en contacto con los autores y temas de la Hegel-Gesellchaft que dejaron una huella indeleble en toda su producción intelectual posterior

Pero Hegel no fue sólo una etapa intermedia sino un compañero inseparable en toda su trayectoria intelectual. Le dedicó libros y multitud de ensayos, desde «El riesgo de Hegel sobre la libertad», «Hegel y los derechos humanos», y otros muchos, hasta el que ha sido su último libro en el que estuvo trabajando durante los últimos años, ya jubilado como profesor emérito, una reflexión madura sobre la Filosofía del Derecho de Hegel que publicaría el año pasado con el título de Mensajes hegelianos (Iustel, 2012).

Y de Hegel al Estado, el otro gran tema en la obra de N. M. ${ }^{a}$ LóPEZ CALERA, que cristalizaría en su obra Yo, el Estado (Trotta, 1992) una «teoría sustancialista que no sustancializadora del Estado», en la que defendía en el fondo una tesis bastante hegeliana: «Que las libertades se "salvan" o se "condenan" en el seno del Estado. No hay, por ahora, otro "lugar" público y colectivo para la realización de las libertades [...] Las libertades individuales dejadas a su juego se destruyen mutuamente, como el neoliberalismo dominante está demostrando de manera muy eficiente. Pero para que se salven es necesario que el Estado sea democrático, un Estado legitimado por la soberanía popular y por el respeto de los derechos humanos». 
Al margen de esos dos grandes temas, N. M. ${ }^{a}$ LÓPEZ CALERA introdujo, dinamizó y participó en importantes debates abiertos en la filosofía jurídica española.

En 1977 organizó un seminario en Granada junto a P. ANDRÉs IBÁÑEZ y M. SAAVEDRA sobre «el uso alternativo del derecho» que fue el germen de un pequeño libro sobre el tema que tuvo una gran repercusión en el seno de la teoría jurídica y la judicatura española y una proyección importantísima en el ámbito latinoamericano.

Además intervino en temáticas tan variadas como el nacionalismo, el terrorismo, el interés publico, o la corrupción y la ética pública. Y, por supuesto, no podemos olvidar su contribución al debate acerca de los derechos colectivos. Una aportación imprescindible en la teoría de los derechos desarrollada en nuestro país. Sobre este tema confesaba que no era un colectivista: «No tengo ninguna convicción dogmática sobre el sentido y el valor de lo colectivo en la vida humana», pero admitía que «hay derechos colectivos porque hay sujetos colectivos y que en el reconocimiento y protección de esos derechos colectivos estaban en juego importantes derechos individuales». Precisamente a los sujetos colectivos dedicó su último libro en activo con el título Los nuevos leviatanes. Una teoría de los sujetos colectivos (Marcial Pons, 2008).

$\mathrm{Al}$ margen de ideologías y de escuelas, el reconocimiento y la autoridad moral de N. M. ${ }^{a}$ López CALERA en el ámbito de la Filosofía del Derecho siempre nos abrió puertas en España y en el extranjero a todos sus colaboradores. Esa autoridad creo que fue decisiva para que se le encargara la organización del Congreso mundial de Filosofía del Derecho en Granada en el año 2005 que contó con la presencia estelar de J. HABermas, pero también de R. Alexy, D. Held, N. Fraser, I. Young, L. Ferrrajoli, B. SANTOS, y un largo etcétera de participantes. El éxito de aquel congreso creo que fue una de sus últimas y mayores satisfacciones en el terreno académico.

$\mathrm{Su}$ trayectoria intelectual fue siempre expresión de compromiso y de independencia. Como apuntaba acertada y cariñosamente A. OlLERO, N. M. ${ }^{a}$ LÓPEZ CALERA «era independiente hasta de sí mismo, de cualquier tentación se sentirse autosatisfecho de sí mismo y de su entorno». Sirvan algunos ejemplos:

Cuando más fácil hubiese sido haberse presentado a las elecciones al Rectorado de la Universidad de Granada en los años ochenta como candidato oficial de la izquierda, él se obstinó en presentar una candidatura independiente en la que estaban integrados desde el propio A. OlLERO a un por entonces jovencísimo L. GARCÍA MONTERO. Aquel experimento, quizá por demasiado independiente, acabó fracasando.

Cuando más fácil hubiese sido subirse al barco de lo políticamente correcto y seguir la ola de la política de proliferación de universidades uniprovinciales, más enérgica era su voz en todos los foros públicos denunciando el sinsentido de dicha política. Estos y otros ejemplos que podrían citarse muestran la facilidad que tenía de nadar a menudo a contracorriente.

En política no le faltaron opciones para asumir responsabilidades y cargos políticos, pero siempre tuvo el reparo y el miedo a perder su independencia de criterio.

N. M. ${ }^{a}$ LÓPEZ CALERA fue un «maestro» en el sentido más convencional que el término tiene en el ámbito académico y universitario, pero fue un maestro sin «escuela». Una expresión más de esa independencia. Nunca formó un grupo más o menos 
homogéneo en cuanto a temáticas y enfoques, sino todo lo contrario. Todos sus colaboradores, desde los primeros como, F. Valls, A. Ollero, M. Maresca, A. Jara o M. SAAVEDRA, hasta las últimas generaciones de profesores que se han ido sumando al Departamento, hemos constituido un grupo heterogéneo y plural en el que han cabido desde el iusnaturalismo al marxismo, la hermenéutica, el utilitarismo, el feminismo y el ecologismo, «analíticos» y «críticos», la argumentación jurídica y la historia del pensamiento jurídico, y bajo su dirección se han realizado tesis de las mas variadas temáticas y enfoques. Esa heterogeneidad y ese pluralismo, junto al respeto por el trabajo ajeno, la discusión racional y la crítica, creo que son notas características del grupo de filósofos del derecho que trabajamos en Granada. Características todas ellas que son también reflejo de la propia personalidad intelectual de N. M. ${ }^{a}$ LÓPEZ CALERA.

Hay tres pasiones, tres vocaciones, tres constantes imprescindibles en la vida de Nicolás: el amor a su ciudad, la dedicación al trabajo universitario y el sostén personal de su familia.

Su compromiso con Granada es incuestionable. No ha existido debate ciudadano en el que no haya participado e intervenido desde su asidua y constante colaboración en la prensa local de Granada. Casi más de mil páginas dan testimonio de su presencia constante en la vida pública y en la reflexión ciudadana. Y el amor por su tierra, no exento de una profunda y sincera autocrítica, sirvieron para que nos dejara un ensayo central para entender las características peculiares de El ser granadino (Comares, 1998).

En la Universidad de Granada constituía todo un referente. Había sido decano, colaborador estrecho en el Rectorado de su amigo F. MAYOR ZARAGOZA, miembro de prácticamente todos los Claustros y Consejos de gobierno. Rectores y candidatos a rectores, decanos y candidatos a decano, compañeros de las más diversas áreas jurídicas y no jurídicas, han buscado su consejo y han recibido su aliento para las más variadas empresas intelectuales.

Su espíritu de servicio público y su dedicación universitaria fueron ejemplares. Era un apasionado de sus clases, algo que cuidaba especialmente, y siempre nos transmitió el respeto y la consideración por el alumno y la responsabilidad social que entraña nuestro trabajo universitario. Cuando, por ejemplo, nos escandalizábamos de algunas decisiones absurdas e incomprensibles de nuestros jueces y magistrados decía que no sólo había que centrar la atención en los que firmaban aquellas sentencias, sino también buscar las responsabilidades en las Facultades de Derecho y en los profesores que habían «amueblado» sus cabezas.

En el terreno personal, Nicolás es impensable sin la presencia inseparable de M. ${ }^{a} \mathrm{~L}$. ESPADA, profesora de derecho internacional, su compañera de vida. Orgulloso pregonaba que su mejor obra —y el mayor regalo— habían sido sus hijas y sus nietos. En sus últimos años — puedo dar fe-lo único que alteró su rutina y su horario espartano de trabajo en el despacho de la Facultad fue el calendario de los partidos de fútbol de sus nietos y los ratos que dedicaba a «maleducarlos» deliberadamente.

No era amigo de homenajes. Tan es así que ni tan siquiera consintió que organizáramos el tradicional libro homenaje con motivo de su jubilación en el año 2008. A lo más que accedió fue a ser entrevistado por sus dos más estrechos y cercanos colaboradores 
-M. SAAVEDRA y M. MARESCA - para el número extraordinario del cincuenta aniversario de los Anales de la Cátedra Francisco Suárez en el año 2010. Y creo que aceptó más por la revista y los entrevistadores que por él mismo. Una entrevista que con su fallecimiento recobra toda su actualidad e interés y a la que me remito ${ }^{1}$ para quien quiera profundizar en la trayectoria intelectual y personal de N. M. ${ }^{a}$ LÓPEZ CALERA.

Por todo ello, creo que el mejor homenaje que se le puede brindar a Nicolás es intentar hacer en la medida de lo posible lo que él hubiera hecho en este caso. Él no hubiera desaprovechado la ocasión para provocar un debate, encontrar un pretexto para ejercer la crítica y, para bien o para mal, en mayor o menor medida, para no dejar indiferente a cualquier asistente a un acto suyo. Estas palabras mías en este acto pretenden ser lo más fieles posibles a ese estilo.

Para ello, permitidme que en este momento introduzca una anécdota personal.

El fallecimiento de Nicolás coincidió en el tiempo con la jubilación por enfermedad de nuestro compañero y amigo M. MARESCA. Cuando preparaba esta intervención, estaba ayudando a Mariano a desmantelar físicamente su despacho, a desempolvar y expurgar los papeles de más de cuarenta años de trabajo en la Universidad. Cuarenta años en los que ininterrumpidamente compartió con Nicolás el trabajo diario en el Departamento, pero también una amistad profunda. Entre aquellos papeles viejos había de todo, pero hubo una carpeta que llamó especialmente mi atención. Era una carpeta con los materiales teóricos y prácticos del curso 1972-1973, textos mecanografiados y anotados personalmente por ambos. En el cuaderno de prácticas, titulado «Derecho y libertad», uno podía encontrar textos de T. DE AQuino, HobBes, Locke, RousseAu, KANT y Hegel, pero también de MARX y WeBER, pasando por AdORNO y HorkHEIMER, o MARCUSE y los textos de las Declaraciones de derechos de 1789 y 1948. Y entre las lecciones teóricas del programa, tras las obligadas sobre el concepto de derecho y la referencia al derecho natural, estaban — repito, en 1972 - derecho y fuerza, derecho y revolución, derecho y cambio social.

La conclusión era obvia: cuán alejado estaba aquel programa de las guías docentes de las asignaturas de Teoría del Derecho de nuestros actuales grados. Es el transcurso inexorable del tiempo, pensé. Aunque hoy no sabría decir cuánto hemos ganado y cuánto hemos dejado atrás en ese trayecto. Aquella carpeta fue una invitación a la reflexión sobre el papel actual de la filosofía del derecho en la formación del jurista, sobre qué tipo de filosofía del derecho y sobre qué modelo de enseñanza del derecho. Una de las preocupaciones constantes de Nicolás.

Su opinión sobre la filosofía del derecho que se hace actualmente en nuestro país era bastante positiva, creía que existía pluralidad y rigor aunque echaba de menos planteamientos críticos y utópicos sobre el derecho, pero sobre todo destacaba que había acabado convirtiéndose en una filosofía jurídica «normalizada» con las de nuestro entorno y tiempo. En cualquier caso, no vislumbraba un futuro claro: «las cosas están mal con la exclusión "de facto" de la filosofía del derecho en las Universidades, que va a tener que refugiarse y trabajar en los "media" y en seminarios de estudio al margen

${ }^{1}$ M. Maresca y M. SAAvedra, «Entrevista a Nicolás M. ${ }^{a}$ López Calera», Anales de la Cátedra Francisco Suárez, 44/2010, 573-581. La mayor parte de las citas textuales utilizadas en esta intervención proceden de esta entrevista. 
de los grados y los posgrados. Tiene mal porvenir, pero su mal porvenir va a afectar al porvenir de nuestras sociedades políticas que van así a incrementar sus déficits sobre valores como la igualdad, la libertad y la dignidad».

Era enemigo de una universidad alejada de la sociedad, como de una formación jurídica de espaldas a la práctica jurídica y a los problemas reales de los ciudadanos. Pero especialmente en sus últimos años asumió públicamente en diversos foros una actitud muy beligerante ante las últimas reformas educativas y, en especial, ante la actual deriva de la Universidad y ante el papel decreciente de asignaturas formativas como la filosofía del derecho en la formación del jurista y, más en general, ante el menguante peso de las humanidades en la enseñanza universitaria:

Un proyecto académico particularmente enfocado a «no pensar»—decía— nunca será un producto razonable de educación superior sino una respuesta obediente a los principios de la rentabilidad y la productividad que alimentan el sistema social vigente.

Por eso, estoy convencido que no desaprovecharía hoy la ocasión para insistir y reivindicar la necesidad de una formación integral del jurista, de proporcionarle materiales de contraste, de la necesidad de una filosofía del derecho entendida como una «teoría radical (que va a la raíz de los problemas) sobre el derecho y sobre la política». No conformarse con lo que el derecho «es» sino afirmar y luchar por su «deber ser», por la posibilidad de «mundos sociales alternativos».

Como defiende M. Nussbaum en el libro Sin ánimo de lucro, que fue el último que personalmente tuve ocasión de comentar con él, «el pensamiento crítico, la imaginación narrativa, la indagación profunda en las cuestiones perennes del ciudadano, nos hacen mejores personas, sí, pero también construyen más y mejor la democracia».

A Nicolás le gustaba recordar, citando a B. BRECHT, que luchar por lo evidente ha sido y sigue siendo dramático, y confesaba que «después de cuarenta años, he disfrutado ética e intelectualmente de esta tarea y me considero feliz por haber servido modestamente a la afirmación de lo evidente: la igualdad y la libertad de la persona humana, de los grupos y de los pueblos más desfavorecidos».

Gracias de nuevo por dedicar este acto a su memoria. 